\title{
DEMOCRACIA E (DES)IGUALDADE NO CONTEXTO BRASILEIRO
}

\section{DEMOCRACY AND (IN)EQUALITY IN THE BRAZILIAN CONTEXT}

\author{
Giancarlo Montagner Copelli ${ }^{1}$
}

\section{RESUMO:}

Este artigo volta-se à análise da convivência entre desigualdade social e democracia, paralelamente, no contexto brasileiro. Para tal, faz um breve escorço, linear, do chamado modelo dos antigos até o formato considerado moderno de democracia, procurando demonstrar a construção histórica da igualdade como fim a ser alcançado. O segundo movimento deste texto volta-se ao contexto brasileiro, a partir de chaves explicativas de viés sociológico, correlacionando-o às premissas anteriormente levantadas. O método é o fenomenológicohermenêutico.

Palavras-chave: Igualdade, Democracia, Brasil, Paradoxo, Cidadania.

\begin{abstract}
:
This paper turns to the analysis of the coexistence between social inequality and democracy, in parallel, in the Brazilian context. To do so, he briefly outlines the so-called model of the ancients to the modern form of democracy, seeking to demonstrate the historical construction of equality as an end to be achieved. The second movement of this text turns to the Brazilian context, based on explanatory keys of sociological bias, correlating it with the premises previously raised. The method is phenomenological-hermeneutic.
\end{abstract}

Keywords: Equality, Democracy, Brazil, Paradox, Citizenship.

\footnotetext{
${ }^{1}$ Doutor em Direito (Área de Concentração em Direito Público) pela Universidade do Vale do Rio dos Sinos, mestre em Direito (Área de Concentração em Direitos Humanos) pela Universidade Regional do Noroeste do Estado do Rio Grande do Sul. Atualmente, em estágio pós-doutoral, com bolsa Capes/PNPD, na Universidade do Vale do Rio dos Sinos. Afiliação: Universidade do Vale do Rio dos Sinos - UNISINOS, Rio Grande do Sul. ORCID: https://orcid.org/0000-0002-8917-4685. Lattes: http://lattes.cnpq.br/9938370828893649.

E-mail: giancarlocopelli@yahoo.com.br
} 


\section{CONSIDERAÇÕES INICIAIS}

Observando, ainda que muito sumariamente, os percursos históricos que envolvem o conceito de igualdade, este texto procura delimitá-lo, de pronto, como uma construção moderna. Tal premissa, mais que o produto de um simples inventário conceitual, é determinante para tornar evidente a impossibilidade de pensá-la como algo pronto, um desde sempre, visão tão cara às frágeis concepções jusnaturalistas. A igualdade, enquanto construção histórica, é portanto um edifício inacabado, cujo avanço projeta-se sempre frente a vários influxos, sejam eles de ordem política e/ou econômica. E é dessa compreensão que se pode, enfim, projetar sólidos alicerces a tal empreendimento.

Assentada como uma ideia moderna, portanto, a igualdade é observada, aqui, como uma espécie de fundamento de outro edifício moderno, qual seja, a democracia surgida na esteira das revoluções liberais. Ocorre, entretanto, que, mais que fundamento, a igualdade é, em boa medida, também dependente da democracia. De outro modo, se por um lado é alicerce que fundamenta, de outro é, também, objeto a ser protegido.

Evidente, tal compreensão coloca a igualdade acima da projeção - resignada - que põe o conceito como condição meramente formal ou, indo além, como uma espécie de obstáculo à liberdade - e vice-versa. Daí importa não apenas delimitar - no sentido de constatar - as tensões verificadas na democracia, sobretudo em países de modernidade tardia ${ }^{1}$, como o Brasil, frente às questões da igualdade, mas, além, de estabelecer uma espécie de ethos mínimo voltado à igualdade.

Não se trata, adianta-se, de análise do Estado Social - como sequência do projeto liberal - e suas crises, sejam elas de ordem fiscal-financeira, ideológica e filosófica ${ }^{2}$, projetando alternativas estratégicas para superar déficits financeiros - para custear as políticas públicas, ou seja, os meios para os fins; tramas burocráticas - sempre associadas às tomadas de decisão e seus questionamentos; e limites de solidariedade - via de regra, estreitos, sobretudo em períodos de caixa vazio. Além disso, adverte-se, não se trata, igualmente, da análise de viés histórico-sociológico, buscando nos limites impostos por características próprias do patrimonialismo e de outras heranças ibéricas, as causas e as razões para nossos déficits de igualdade na democracia.

Feitas estas observações - e com o objetivo de analisar essa paradoxal convivência entre desigualdade social e democracia no contexto brasileiro - o que se projeta é um duplo 
movimento. O primeiro, linear e bastante sucinto, assenta a igualdade como uma construção histórica e a põe em relação com a democracia em seu formato também moderno, ou seja, aquele diferente da experiência grega. Já o segundo, dividido em duas partes, relaciona tal modelo às especificidades brasileiras - em um primeiro momento - e ao caminho em busca de uma sociedade, efetivamente, igualitária - em uma segunda etapa. O método é o fenomenológico-hermenêutico, buscando desvelar, através do revolvimento do chão linguístico encoberto pela tradição ${ }^{3}$, novas possibilidades de análise ${ }^{4}$.

\section{A CONSTRUÇÃO DA IGUALDADE}

A desigualdade, seja tanto do ponto de vista político quanto do social, gozou de ampla aceitação ao longo da História da humanidade (BEDIN, 2002), e não foi uma característica apenas de regimes não democráticos, como as monarquias absolutistas, por exemplo. Mesmo em sistemas democráticos, como o modelo ateniense na Antiguidade - ou a República Romana -, a igualdade social não era um fim a ser alcançado, como bem pontua Dahl (2012), já que tais modelos pressupunham a igualdade apenas em relação à participação na vida pública, atrelando esta, por sua vez, à condição de cidadão ${ }^{5}$.

Tal pensamento, ao excluir pela diferença, também foi reforçado pelas teorias platônicas e aristotélicas ${ }^{6}$, perpassando, através da tradição, “todo o período medieval” (BEDIN, 2002, p. 25), muito embora o Cristianismo, através do Catolicismo Romano, tenha defendido a igualdade perante Deus - mas não entre os homens ${ }^{7}$. E, mesmo após a Reforma Protestante ${ }^{8}$, que através da parcela que rompe com Roma formula as primeiras teses de igualdade entre os homens neste mundo (BEDIN, 2002, p. 27), "a completa inversão entre desigualdade e igualdade, no entanto, somente se concretizou com os pensadores políticos do século XVII e XVIII".

Desse modo, é possível verificar que a democracia, no sentido clássico ou antigo do termo, não pode ser associada à noção moderna de igualdade, ou seja, a dos pensadores políticos dos séculos XVII e XVIII. Afinal, conforme observado neste brevíssimo inventário da democracia na Antiguidade - através do exemplo da Grécia Clássica -, a igualdade era necessariamente vinculada ao conceito de cidadania que, como se destaca introdutoriamente, era claramente seletivo. Somente a partir dos ideais que embasaram as chamadas Revoluções Liberais, como a Francesa, em 1789, e a Norte-americana, em 1776 - ou seja, após uma longa lacuna temporal que atravessa a Antiguidade e todo o Medievo - é que a igualdade entre os 
homens passou a ser considerada não somente uma das forças a promover tais revoluções, mas, sobretudo, a relacionar a noção de igualdade plena como indissociável da ideia de democracia, regime que então ressurgia cerca de 2.500 anos após a experiência grega. Neste sentido, segundo Rosanvallon (2012, p. 21), tanto a democracia enquanto regime político, ou seja, aquela associada à soberania popular e às liberdades civis e políticas, quanto a democracia enquanto sociedade de iguais, não eram possibilidades díspares. Afinal, "hay que se recordar que la igualdad e la liberdad, de buen grado presentadas hoy como antinómicas ${ }^{9}$, [...] eran compreendidas como indisociables en el momiento de la Revolución”.

Entretanto, ainda para este autor, ao passo que o regime democrático passou a avançar sobre um número cada vez maior de nações no globo ${ }^{10}$, a partir das revoluções já citadas, alcançando, consequentemente, um contingente também cada vez maior de indivíduos sob esses mesmos valores, houve, contraditoriamente, uma espécie de ruptura com o passado recente: de um lado, a democracia, enquanto regime político, cresceu. De outro, as sociedades tornaram-se cada vez mais desiguais. Ou seja, a igualdade, para ele, foi dissociada da liberdade, bem exercitada, sobretudo enquanto extensão dos direitos civis, no gozo de direitos políticos.

\section{O BRASIL, A DEMOCRACIA E A DESIGUALDADE}

A constatação de Rosanvallon (2012), elaborada a partir do exemplo francês, também pode ser verificada no Brasil. Afinal, é possível observar um notável crescimento, ao longo da História, da participação dos cidadãos na política brasileira, sobremodo, a partir da chamada Segunda República. Ou seja, é possível verificar o crescimento da democracia estritamente enquanto regime político e, paralelamente, constatar que o Brasil permanece como um dos países mais desiguais do mundo, coadunando sua condição, portanto, à observação do pensador francês acerca desta espécie de "paradoxo democrático", para usar a feliz expressão de Bernardo Sorj (2004, p. 13) em todo o mundo.

De fato, enquanto o Brasil apresenta significativas disparidades em diversas circunstâncias entre seus cidadãos, ao longo da História o país desnudou importantes avanços no que se refere aos direitos políticos, como se pode observar através da síntese de fio histórico proposta por Vera Chaia (2010), ao inventariar a evolução do processo de participação política no Brasil ${ }^{11}$.

Segundo essa pesquisadora, com a República, embora ainda fossem perceptíveis muitas restrições, houve, também, avanços na participação política ${ }^{12}$ : ao passo que não havia mais 
limitação de renda, como ocorria no Império, mulheres, menores de 21 anos, analfabetos, praças e religiosos enclausurados continuavam sem poder votar. Ou seja, ainda que muitos grupos fossem excluídos do processo, ao menos o exercício político do voto não era mais condicionado à renda, alargando, ainda que de forma muito discreta, o universo de eleitores.

Também de maneira pálida, a participação eleitoral avançou em 1932 e 1934, com o Código Eleitoral e a Constituição Federal, respectivamente: a idade mínima para a participação do processo eleitoral foi reduzida para 18 anos, e as mulheres - somente as que trabalhavam fora - passaram a exercer o direito ao voto, facultando, novamente, o alargamento do contingente de eleitores.

Do mesmo modo, embora tenha havido uma importante interrupção no avanço dos direitos políticos, de 1937 a $1945^{13}$, com a implantação do Estado Novo de Getúlio Vargas ${ }^{14}$, e por outra longa lacuna temporal, com o Regime Militar, de $1964^{15}$ até 1985 , ano que assinala a redemocratização do país, tais direitos continuaram a avançar. E, a partir de 1989, data que marca a primeira eleição direta para presidente da República desde 1960, o voto já é livre, secreto, facultativo para cidadãos entre 16 e 18 anos de idade e maiores de 70 anos e analfabetos, e independente de gênero (CHAIA, 2010). Ou seja, tal direito, que muito bem pode representar o crescimento da democracia enquanto regime político, como predisse Rosanvallon (2012), passou a englobar um imenso contingente de cidadãos, não apenas se comparado aos sobressaltos autoritários de 1937 a 1945 e de 1964 a 1985, mas também em relação às possibilidades de participação política no Império, na Primeira República e no período democrático compreendido entre 1945 e o Golpe de 1964.

Contudo, de fato, tal crescimento da democracia, enquanto regime, não foi capaz de fazer do Brasil uma sociedade de iguais. Afinal, como bem observa Bedin (2006, p. 08), paralelamente ao avanço democrático, o Brasil permaneceu "um país [...] absolutamente injusto, tendo grande parte de seus cidadãos [...] em condições miseráveis, sem os recursos mínimos para uma existência com dignidade como pressupõe o Estado de Direito". Assim, o Brasil mostra-se, paradoxalmente, como uma democracia, com um Estado de Direito ${ }^{16}$ de sentido meramente semântico, mas não - ainda na esteira da análise de Rosanvallon (2012) como uma sociedade de iguais.

Diante desse quadro - de democracia consolidada paralelamente à manutenção da desigualdade -, Emil Sobottka (2009, p. 153 - grifo nosso) questiona se não "aceitamos com alguma naturalidade que a questão proposta hoje para esta reflexão seja sobre quanta desigualdade a democracia pode suportar". Para este autor, tal reflexão - que permite analisar 
as conclusões de Rosanvallon (2012) - denota duas possibilidades: 1) A resignação diante da desigualdade, ou seja, a percepção deste fenômeno social como um dado pronto e, por isso mesmo, natural e inevitável, restando saber, portanto, até que ponto podemos ser democráticos e, paralelamente, desiguais; e 2) A preocupação sobre a forma como as sociedades, em especial a brasileira, estão estruturadas, de modo que o foco do debate passa a ser, então, como podemos ser democráticos e, ao mesmo tempo, desiguais.

Naturalmente, a primeira possibilidade de análise desloca a ideia de igualdade do conceito de democracia, propondo necessariamente hipóteses voltadas a um limite que, ultrapassado, colocaria em xeque o próprio regime político. Contudo, se o Estado Democrático "é o tipo ideal de Estado de quem se coloca do ponto de vista do direito" (BOBBIO, 2000, p. 23), a resignação em relação à desigualdade implica não somente um fim, mas também a conclusão de que a democracia é, nesse sentido, ineficaz, abrindo caminho para outras formas políticas que, invariavelmente, se colocam não mais do ponto de vista do direito, mas do poder. De outra forma, é possível concluir, também, que tal análise não explica o distanciamento entre democracia e igualdade, como predito por Rosanvallon (2012), e tampouco busca alternativas para a superação deste paradoxo, mas justifica este distanciamento, encerrando esta espécie de antinomia como um axioma das sociedades modernas e democráticas.

De outra banda, analisar a questão proposta a partir da organização social - segunda alternativa de análise assinalada por Sobottka (2009) -, ao passo que faculta hipóteses que colocam a desigualdade como produto da dinâmica social - e não como uma causa absoluta a se resignar - permite analisar o fenômeno na gênese ou dentro da própria democracia, acenando, portanto, para uma contradição (SORJ, 2004). Esta, por sua vez, se observada como consequência da estruturação social, pode ser revertida ou pensada a partir do modelo democrático que, como vimos, é, para Bobbio (2000), aquele que se coloca sob o ponto de vista do direito, e não do poder. Assim, se o núcleo da discussão volta-se à formação e à organização das sociedades, cumpre, portanto, recapitular, ainda que de maneira sintética, a estruturação social que deu forma ao modelo atual - ou moderno ${ }^{17}$, como inscreve Sobottka (2009).

\subsection{NA GÊNESE DO PARADOXO, UM LONGO CAMINHO (AINDA) A PERCORRER}

Desse modo, voltando necessariamente a atenção ao modelo idealizado e difundido a partir do século XVIII - enquanto ponto de partida para a compreensão das sociedades 
modernas -, oportuna é a observação de Claude Lefort (1991), ao destacar que tais conformações sociais moldaram e foram moldadas pela democracia, à medida que se assentaram justamente na luta dos liberais contra as desigualdades e privilégios que caracterizaram o Antigo Regime. Sobottka (2009), em complemento, destaca por sua vez que prevaleceu como fundamentação a essa inversão - do Antigo Regime ao modelo liberal ou moderno - o argumento de que todos os indivíduos eram naturalmente iguais ${ }^{18} \mathrm{e}$, por isso, assim deveriam ser reconhecidos socialmente ${ }^{19}$. Contudo, a igualdade, para este autor, foi observada apenas do ponto de vista formal, sustentando apenas o igual direito de ser livre. E, "em decorrência disto, cabe a elas [às pessoas, consideradas iguais] escolher livremente como querem organizar sua vida" (SOBOTTKA, 2009, p. 154 - colchetes e grifo nossos; parênteses do autor)

A partir desta observaçãor, é possível concluir a prevalência de um direito fundamental - a liberdade - sobre outro - a igualdade -, na base constitutiva das sociedades modernas, ou seja, daquelas estruturadas a partir do século XVIII e denominadas democracias. De outro modo, é possível dizer que o ideal de igualdade pôs abaixo o privilégio - de um único indivíduo ou de poucos - de decidir como se governa ou quem governa, criando prerrogativas idênticas entre os indivíduos em sentido político, alargando também a liberdade para se viver da maneira julgada mais apropriada ${ }^{20}$. Mas esse mesmo ideal de igualdade não visou pôr abaixo o privilégio que permitia condições diferenciadas - do ponto de vista material - para a vida em sociedade muito embora fosse esse um ideal revolucionário no século XVIII, conforme Rosanvallon (2012) - favorecendo, portanto, a existência da desigualdade dentro de um regime democrático, sem constrangimentos, como assinala Sobottka (2009).

Assim, evidencia-se a coexistência de democracia e desigualdade como um paradoxo não apenas propriamente brasileiro, mas, sim, comum - em maior ou menor grau - a todas as sociedades modernas, fundadas a partir dos ideais liberais do século XVIII. Entretanto, sociedades como a brasileira, por exemplo, ainda diferem daquelas consideradas centrais porque, naquelas "o Direito cria uma igualdade formal entre todos [comprometendo] os cidadãos e toda a nação a respeitar e a cumprir consequentemente os direitos e deveres inerentes à cidadania"21 (SOBOTTKA, 2009, p. 154-159).

Embora essas sociedades ditas centrais não sejam exatamente exemplos de organizações sociais igualitárias, Sobottka (2009) refere, como apoio à sua afirmação, tal comprometimento a sociedades como a Alemanha, a França e a Inglaterra, países que, em tese, construíram espaços comuns - entre os indivíduos-cidadãos - para seus respectivos conceitos de cidadania ${ }^{22}$ 
através de noções pré-políticas, como pertinência étnico-cultural, ou relações jurídicas de pertinência $^{23}$. Entretanto, no Brasil - bem como em outras sociedades periféricas -, tal igualdade formal, fruto da tradição liberal que funda as sociedades modernas sob o ideal democrático, não supôs, nas bases estruturantes destas mesmas sociedades (COSTA, 1987; SALES, 1992), o "sentimento de um destino comum" (SORJ, 2004, p. 22), ou seja, o caminho lógico da igualdade determinada pela cidadania, independentemente desta construção ocorrer por noções de pertinência pré-política ou pertinência jurídica. Ao contrário, consolidou "uma longa tradição de oferta de assistência para os necessitados ${ }^{24}$ [...]. A inclusão em relações de clientelismo ou compadrio certamente tem maior relevância que um comprovante de cidadania" (SOBOTTKA, 2009, p. 158).

Uma explicação possível para a afirmação acima, ao dar maior peso às relações clientelistas ou de compadrio em detrimento de direitos sociais - que em tese deveriam ser assegurados por vínculos de cidadania -, pode ser encontrada na forma de estruturação social do Brasil. Ou seja, somadas as características de formação das sociedades modernas, fundadas a partir dos ideais liberais do século XVIII, nossa "democracia inesperada", como inscreve Sorj (2004, p. 13), também decorreria de contextos muito próprios ${ }^{25}$. De fato, para José Murilo de Carvalho (2002, p. 219-220), tais contextos, relacionados especificamente à gênese da sociedade brasileira, levaram a uma completa inversão na sequência dos direitos, segundo a lógica descrita por Marshall ${ }^{26}$, favorecendo as relações pessoais em detrimento dos vínculos de cidadania. Assim, "aqui, primeiro vieram os direitos sociais, implantados em período de supressão dos direitos políticos e de redução dos direitos civis por um ditador que se tornou popular [...]. Depois vieram os direitos políticos”.

Este autor, embora defenda a existência de outros caminhos possíveis para a construção da cidadania, afirma que a inversão da pirâmide dos direitos afetou o tipo de democracia que se tem no Brasil. Não por outra razão Teresa Sales (1992, p. 35) vai afirmar, em sua tese de livre-docência, que "o domínio do liberalismo pouco contribuiu para a instauração dos direitos básicos de cidadania", já que, historicamente, esses mesmos direitos sempre foram - e continuam sendo, muitas vezes ${ }^{27}$ - vistos como concessões, e não propriamente como direitos, comprometendo o "metafundamento social da cidadania moderna [que] é a dupla indivíduonação ou indivíduo-povo" (SORJ, 2004, p. 23 - grifo e colchetes nossos).

Evidentemente, o binômio aludido por Sorj (2004), em complemento à afirmação de Sales (1992), apresenta contradições que vão além das nossas peculiaridades. Afinal, os princípios que fundam a cidadania moderna - indivíduo e comunidade - “apresenta[m], desde 
suas origens, uma constante tensão" (SORJ, 2004, p. 27 - colchetes nossos). E, por isso mesmo, compreender nossas características de formação social - como, entre outras, o clientelismo e essa percepção, como quer Carvalho (2002), de um Estado todo-poderoso, por exemplo - como causa exclusiva para uma espécie de déficit de cidadania no Brasil, ignorando as antinomias presentes nas demais democracias, levaria à confusão entre concepções ideais - um dever ser, geralmente associado, apesar das imperfeições já apontadas, aos países desenvolvidos, centrais - e contextos verificáveis, empíricos - um ser, longe da idealidade, comumente associados a países considerados periféricos, como o Brasil. Por isso, em que pesem nossas características próprias na formação social brasileira - enquanto contribuição para um déficit de cidadania -, não lhes cabe, assim, uma exclusividade nesse sentido. Afinal, se têm importância nossas características próprias, pesam também as contradições inerentes a qualquer democracia.

Assim, é possível assinalar que a democracia, independente da sociedade em que se encontra, seja central ou periférica, convive tanto com contradições mais ou menos gerais ${ }^{28}$ quanto com paradoxos peculiares, e tanto a igualdade quanto a liberdade, bem como as questões que envolvem a cidadania, de modo geral, formam contextos centrais nesta discussão. Por isso, como já visto com Rosanvallon (2012), se o ideal de igualdade vem, em todo o globo, se desprendendo do ideal de democracia, evidentemente essa espécie de tendência mundial - e negativa - também reflete no Brasil.

Esse é, precisamente, o ponto, portanto: se nossas características de formação social não são responsáveis exclusivas pela desigualdade, não se pode, por outro lado, deixar de levar em consideração paradoxos democráticos globalmente verificados. Afinal, se os vínculos de cidadania - inclusive aqueles tênues, que não evitam altos níveis de disparidade entre os cidadãos - são construções históricas e ligados a cada sociedade em particular (SORJ, 2004), não se pode pensar tal fenômeno social nem somente a partir de uma tendência ou característica que afeta a totalidade das sociedades modernas, em especial as consideradas democráticas, nem apenas a partir das características peculiares a cada nação.

\section{CONCLUSÃO}

Disso tudo é possível concluir, por fim, que no Brasil pesou a antinomia entre igualdade e liberdade, como em outras democracias, já que tal regime político pressupõe apenas igualdade formal, ou seja, perante à lei, e não material, a despeito de ser esta igualdade, também, um dos 
ideais contidos nas revoluções do século XVIII, como observado, sobretudo, a partir de Pierre Rosanvallon (2012) e Emil Sobbotka (2009).

Contudo, nossa estruturação social, do Brasil Colônia até a contemporaneidade, fez com que vínculos de cidadania sempre tivessem menos peso que relações clientelistas, como se pôde depreender das análises de José Murilo de Carvalho (2002) e Teresa Sales (1992). E, assim, a democracia brasileira difere das de muitos países centrais - mesmo levando em conta seus paradoxos gerais e peculiares - que, através da igualdade formal e do Estado de Bem-estar Social, alargaram a percepção de um destino comum, minimizando, assim, o desequilíbrio do metafundamento da cidadania moderna, ou seja, do binômio indivíduo-nação, visto com Bernardo Sorj (2004).

E, desse modo, a histórica desigualdade social brasileira - seja legitimada pelos vínculos de sangue, como foi do Brasil Colônia ao Brasil Moderno, seja pela apropriação diferenciada dos mecanismos capazes de produzir valor, forma contemporânea de legitimação deste fenômeno social - permanece alargada, a despeito da democracia, defrontada, ainda, com o favor e a concessão - e não com o direito - como ferramenta para seu enfrentamento.

Evidenciar esses entraves, por fim, não serve ao propósito de acenar para uma espécie de limite à democracia e, menos ainda, desacreditá-la. Pensar soluções em busca de uma sociedade de iguais implica, necessariamente, pensar a partir do modelo democrático. Nossas deficiências são, afinal, problemas a que estão sujeitas todas as democracias reais, cujos objetivos devem ser, sempre, a aproximação das democracias ideais, ou seja, aos modelos que, em essência, já correspondem, na possibilidade de se trilhar o longo e histórico caminho dos direitos, enfim, a uma sociedade de iguais.

Notas

${ }^{1}$ Como costuma referir em suas obras o professor Lenio Luiz Streck. Por todas, seu Hermenêutica Jurídica e(m) crise (2014).

${ }^{2}$ Ou seja, no contexto de crise do Estado - em todas as suas possibilidades - como vai pontuar Jose Bolzan de Morais (2011) no Brasil.

${ }^{3}$ Para Heidegger, a fenomenologia tem como uma de suas principais características justamente tal possibilidade FIGAL, 2005).

${ }^{4}$ Para mais, ver, por todos, Ernildo Stein (1991).

${ }^{5}$ Conforme Dahl (2012, p. 32-33 - grifo nosso; parênteses do autor), a cidadania era condição exclusiva de homens nascidos em Atenas, filhos de pai e mãe atenienses, adultos. Crianças, mulheres, escravos e metecos, ou seja, estrangeiros, não eram considerados cidadãos: “A cidadania era, para todos os efeitos, um privilégio hereditário baseado em laços primordiais de família (embora a cidadania fosse privilégio herdado apenas pelos homens)".

${ }^{6}$ Segundo Dahl (2012), Platão e Aristóteles, críticos da democracia, defendiam diferenças naturais entre os seres humanos. 


\begin{abstract}
${ }^{7}$ Importante, nesse sentido, a observação de Bielefeldt (2000, p. 149), demonstrando que, de fato, a igualdade pregada através do Cristianismo não se referia a este mundo: "Que a ideia da semelhança divina de todos os seres humanos não possa se condicionar ao reconhecimento de direitos iguais para todos, comprova-se pelo fato de a escravidão não ser questionada, em princípio, nem no Antigo Testamento nem no Novo Testamento".

${ }^{8}$ Souza (2009, p. 112 - grifo nosso; parênteses do autor) salienta, neste sentido, que, através do protestantismo, "a dupla moral (faça o que eu digo e não faça o que eu faço) típica das sociedades tradicionais, inclusive no Ocidente pré-moderno católico, que exigia trabalho dos inferiores para manter o ócio dos superiores (seja na sociedade como um todo, seja na Igreja), passa a ser duramente criticada como a suprema hipocrisia".

9 Sen (s/d), em consonância com Rosanvallon (2012), também observa que, atualmente, há uma tensão, de fato, entre igualdade e liberdade no debate contemporâneo.

${ }^{10}$ Segundo Pinker (2013, p. 386), a “[...] Europa Meridional tornou-se totalmente democrática nos anos 1970, e a Europa Ocidental, no começo dos anos 1990. Atualmente, o único país europeu classificado como autocracia é Belarus, e todos, menos a Rússia, são democracias no pleno sentido da palavra. Também nas Américas e em importantes países desenvolvidos no Pacífico, como Coreia do Sul e Taiwan, predominam as democracias".

11 Aqui, referimo-nos à participação dos cidadãos em relação ao voto como exemplo da ampliação da democracia enquanto regime político, também levando em consideração a definição de Bobbio (2000, p. 22), na qual por "regime democrático entende-se primariamente um conjunto de regras de procedimento para a formação de decisões coletivas, em que está prevista e facilitada a participação mais ampla possível dos interessados".

${ }^{12}$ Segundo Chaia (2010), logo após a independência em relação à metrópole portuguesa, em 1822, somente homens acima de 25 anos, com renda anual líquida de 100 mil réis - depois ampliada para 200 mil réis, em 1881 - eram considerados eleitores. $\mathrm{O}$ voto era censitário, havia uma série de limitações que estreitavam as possibilidades para ser candidato, e o imperador ainda decidia, a partir de uma lista tríplice, quais seriam os membros do Legislativo. A participação era,
\end{abstract} portanto, mínima.

${ }^{13}$ A partir de 1945, ocorrem algumas mudanças significativas na participação dos processos eleitorais e, também, muitos paradoxos podem ser observados. Bom exemplo é o fato de mendigos e analfabetos passarem a exercer direito a voto e, paralelamente, a condição de eleitor não depender apenas do alistamento nos Tribunais Regionais Eleitorais, mas também do preenchimento de um formulário nos locais de trabalho dos eleitores (CHAIA, 2010). Ora, mendigos não têm local de trabalho, e analfabetos não podem, evidentemente, preencher formulários.

14 “O argumento utilizado [...] era de que faltava capacidade e maturidade ao povo brasileiro e que somente esta elite política poderia representar e construir a nação brasileira. Todos os cargos eletivos foram eliminados, a escolha dos governadores e prefeitos passou a ser comandada pelo governo central, e o Poder Legislativo, em todas as esferas, foi fechado" (CHAIA, 2010, p. 03).

15 "Vários casuísmos foram criados para controlar o processo eleitoral: decretos-leis, atos institucionais, reformas no sistema partidário brasileiro, fechamento do Congresso Nacional, cassações, censura aos meios de comunicação, supressão dos direitos políticos, prisões e banimento políticos" (CHAIA, 2010, p. 04).

${ }^{16}$ Bedin (2006, p. 06-07 - grifo e parênteses do autor; colchetes nossos), ao conceituar Estado de Direito como: “[...] um Estado subordinado ao direito, que defende os direitos fundamentais e a segurança de seus cidadãos e que tem por base o princípio da razoabilidade, de responsabilidade por seus atos e do respeito da via judicial [e que,] Além disso, estrutura-se a partir da divisão dos poderes e da descentralização de suas atividades, sendo a sua administração orientada pelo princípio da legalidade e voltada à supremacia dos princípios de liberdade e da igualdade, sem nunca afastar o fundamento popular do poder e a defesa do bem público", conclui seu acolhimento na estrutura jurídicoinstitucional brasileira: "Com efeito, a Constituição Federal em vigor no país define, de forma explícita, o Estado Brasileiro como Estado Democrático de Direito e o fundamenta na cidadania, no pluralismo político e na dignidade da pessoa humana (Art. $1^{\circ}$ )".

${ }^{17} \mathrm{O}$ mundo moderno apresenta, segundo Sorj (2004), diferentes formas de sociedade e regimes políticos, como aqueles encontrados em países islâmicos, os sob o viés do comunismo, e os capitalistas, como as democracias liberais. É sobre este último modelo, considerado moderno, que nos referimos neste estudo.

${ }^{18}$ Para Bobbio (2004, p. 21), a fundamentação jusnaturalista ou "a ilusão de um fundamento absoluto, foi um obstáculo à introdução de novos direitos, total ou parcialmente incompatíveis com aqueles. Basta pensar nos empecilhos colocados ao progresso da legislação social pela teoria jusnaturalista do fundamento absoluto da propriedade: a oposição quase secular contra a introdução dos direitos sociais foi feita em nome do fundamento absoluto dos direitos de liberdade. O fundamento absoluto não é apenas uma ilusão; em alguns casos, é também um pretexto para defender posições conservadoras".

${ }^{19}$ Esse ideal precede o século XVIII e já se encontra nos discursos do século XVII. Bom exemplo vem de Dahl (2012, p. 48-49), ao relembrar um trecho do tratado An Arrow Against All Tyrants, de Richard Overton, um leveller britânico, em 1646: "Pois, pelo nascimento, todos os homens são iguais".

${ }^{20}$ Esta última prerrogativa, para Touraine (2012, p. 345), não pode, na verdade, ser garantida, pois está entrelaçada ao mercado, e este "não garante nem a igualdade de oportunidade de todos, nem a orientação dos recursos para a satisfação das necessidades mais sentidas". Entretanto, importante ressaltar que, segundo Sobottka, (2009), o Estado de Bem-estar 
Social, pela via política, busca, ainda que também com muitas limitações, alterar o equilíbrio desigual entre liberdade e igualdade.

${ }^{21}$ Cidadania, aqui, compreendida dentro do conceito de Sorj (2004, p. 22 - parênteses do autor), ou seja, "uma instituição que oferece um título de propriedade particular: um bilhete de entrada para uma comunidade nacional, que dá acesso a um conjunto de direitos - bilhete que se obtém mediante um sistema de critérios (por exemplo, local de nascimento ou nacionalidade dos pais) distribuídos pelo poder constituído", mas também alargada pelo Estado de Bem-estar Social, ou seja, o que para Sobottka (2009, p. 155 - colchetes nossos) constituía "esta nova concepção de direito [que] passou a legitimar a redistribuição, pela via política, de bens que o mercado, quando deixado à sua própria sorte, alocava de forma crescentemente desigual".

${ }^{22}$ Falamos em respectivos conceitos de cidadania por compreender que, embora haja uma delimitação geral, como a explicitada na nota de rodapé anterior, os conteúdos de tais conceitos são o resultado de construções históricas, variando, portanto, de um lugar ou país a outro (SORJ, 2004).

${ }^{23}$ Mesmo nas relações jurídicas, Souza (2009, p. 400-401 - colchetes nossos) adverte que "a lei da igualdade só possui realidade efetiva nas sociedades que, a partir de uma mobilização social [equalizou as] condições das classes inferiores [...] Essa é a diferença que explica efetivamente a distância social de sociedades modernas periféricas como a brasileira e as sociedades modernas centrais".

${ }^{24}$ Longa tradição de oferta de assistência aos necessitados que, através da lição de Sobottka (2009), permite concluir que tais favores limitaram, historicamente, a noção de cidadania no Brasil, ao contrário do que deve ocorrer, em tese, com a ampliação de direitos sociais através do Estado de Bem-estar Social.

${ }^{25}$ Os contextos aqui aludidos referem-se ao fato de que, tal qual na Europa do século XVIII, os ideais liberais, aqui, também atenderam às demandas de uma elite já constituída, de modo que a independência da metrópole - em 1822 , através da criação do Império Brasileiro - visou apenas à emancipação do fisco português, liberando, segundo Costa (1987), as massas do próprio processo de independência. Ou seja, a independência não foi nem do povo nem para o povo, mas, sim, de uma elite e para uma elite. Além disso, importante recordar que, com o advento da República, em 1889, o governo buscou igualmente atender às expectativas dos grandes proprietários (CARVALHO, 1987), de modo que o povo, constituído por indivíduos sem vínculos de cidadania, participou de "um projeto político-econômico que não fora por eles idealizado e do qual muito menos foram os maiores beneficiados" (VICENTINO, 1999, p. 147), de forma que qualquer traço de cidadania dependeu, desde o Brasil Colônia, exclusivamente do favor.

${ }^{26}$ Segundo Sorj (2004, p. 25), no modelo de Marshall "a cidadania teve como motor a expansão do ideal de igualdade jurídica para as esferas política e econômica. A igualdade perante a lei teria promovido a luta pela igualdade de condições de participação política, [...] e esta teria permitido o avanço dos direitos sociais".

${ }^{27}$ Carvalho (2002, p. 223-224) salienta que, hoje, “o papel dos legisladores reduz-se, para a maioria dos votantes, ao de intermediários de favores pessoais perante o Executivo. O eleitor vota no deputado em troca de promessas de favores pessoais; O deputado apoia o governo em troca de cargos e verbas para distribuir entre seus eleitores. Cria-se uma esquizofrenia política: os eleitores desprezam os políticos, mas continuam votando neles na esperança de benefícios pessoais".

${ }^{28}$ Entre os paradoxos apontados como gerais, importante a observação de Sorj $(2004$, p. 29) que, sem distinções entre esta ou aquela sociedade, pondera: "Os diversos esforços de criação de modelos societários navegaram, e ainda navegam, entre aqueles que, em nome dos direitos individuais, se recusam a aceitar que o Estado garanta uma maior igualdade $\mathrm{e}$ aqueles que, em nome da igualdade, se dispõem a delimitar, ou mesmo eliminar, as liberdades individuais" (SORJ, 2004, p. 29). Touraine (2012, p. 344), nesse mesmo sentido, diz que a "história da democracia [...] é a história da separação progressiva desses dois princípios, da soberania popular e dos direitos do homem. A ideia de soberania popular tendeu a deformar-se numa ideia de um poder popular que faz pouco caso da legalidade e se enche de aspirações revolucionárias, enquanto a defesa dos direitos do homem muitas vezes reduziu-se à defesa da propriedade".

\section{REFERÊNCIAS}

BARROS, Ricardo Paes de. (et. al). A queda recente da desigualdade de renda no Brasil. Rio de Janeiro: $\quad 2007 . \quad$ IPEA, Disponível em: http://repositorio.ipea.gov.br/bitstream/11058/1745/1/TD_1258.pdf. Acesso em: 12.07.2014.

BEDIN, Gilmar Antonio. Os direitos do homem e o neoliberalismo. 3 ed. Ijuí: Editora Unijuí, 2002. 
. Estado de direito e desigualdades sociais: uma leitura da exclusão social a partir da realidade brasileira. In: BONETI, Lindomar Wessler et. al. (Org.). Conceitos e dimensões da pobreza e da exclusão social: uma abordagem transnacional. Ijuí: Editora Unijuí, 2006.

BIELEFELDT, Heiner. Filosofia dos Direitos Humanos: fundamentos para um ethos de liberdade. Tradução de Dankwart Bernsmüller. São Leopoldo: Unisinos, 2000.

BOBBIO, Norberto. O futuro da democracia. Tradução de Marco Aurélio Nogueira. São Paulo: Paz e Terra, 2000.

Elsevier, 2004.

A Era dos Direitos. Tradução de Carlos Nelson Coutinho. 13 reimp. Rio de Janeiro:

BOLZAN de MORAIS, Jose Luis. As crises do Estado e da Constituição e a transformação espaço-temporal dos Direitos Humanos. Coleção Estado e Constituição - 1. 2. ed. Porto Alegre: Livraria do Advogado Editora, 2011.

BRAGATO, Fernanda Frizzo. Direitos humanos além da lógica formal do princípio da igualdade: uma leitura a partir do princípio da não discriminação. In: STRECK, Lenio Luiz; ROCHA, Leonel Severo; ENGELMANN, Wilson (Orgs.). Constituição, Sistemas Sociais e Hermenêutica: Anuário do Programa de Pós-Graducação em Direito da Unisinos/Mestrado e Doutorado, n. 10. Porto Alegre: Livraria do Advogado; São Leopoldo: Unisinos, 2013.

BRASIL. Constituição Federal. Brasília: Senado Federal, 1988. Disponível em: <http://www.planalto.gov.br/ccivil_03/constituicao/constituicaocompilado.htm>. Acesso em: 16.09. 2014.

CARVALHO. José Murilo de. Cidadania no Brasil: o longo caminho. 3 ed. Rio de Janeiro, 2002.

CHAIA, Vera. A longa conquista do voto na história política brasileira. Disponível em: http://www.pucsp.br/fundasp/textos/downloads/O_voto_no_Brasil.pdf. Acesso em: 04.07.2014.

COSTA, Emília Viotti da. Da Monarquia à República: momentos decisivos. 5 ed. São Paulo: Editora Brasiliense, 1987.

DAHL, Robert. A democracia e seus críticos. Tradução de Patrícia de Freitas Ribeiro. São Paulo: WMF Martins Fontes, 2012.

FERREIRA, Francisco. Os determinantes da desigualdade de renda no Brasil: luta de classes ou heterogeneidade educacional? Rio de Janeiro: Pontifícia Universidade Católica de Rio de Janeiro, 2000.

Disponível em: http://www.empreende.org.br/pdf/Programas\%20e\%20Pol\%C3\%ADticas\%20Sociais/Desigualdade $\% 20 \mathrm{de} \% 20 \mathrm{renda} \% 20 \mathrm{no} \% 20 \mathrm{Brasil} . p d f$. Acesso em: 02.05.2014. 
FIGAL, Günter. Martin Heidegger: fenomenologia da liberdade. Tradução de Marco Antônio Casanova. Rio de Janeiro: Forense Universitária, 2005.

FRASER, Nancy. Da redistribuição ao reconhecimento? Dilemas da justiça numa era "póssocialista". Tradução de Julio Assis Simões. In: Cadernos de Campo, n. 14/15, 2006. Disponível em: $\quad$ http://scholar.google.com.br/scholar?cluster=10006775427791380785\&hl=ptBR\&lr=lang_pt\&as_sdt=0,5. Acesso em: 04.09.2014.

LEFORT, Claude. Pensando o político. Ensaios sobre democracia, revolução e liberdade. Tradução de Eliana M. Souza. Rio de Janeiro: Paz e Terra, 1991.

MINISTÉRIO DA EDUCAÇÃO. Índice de Desenvolvimento da Educação Básica 2013. Disponível em: http://ideb.inep.gov.br/resultado/resultado/resultadoBrasil.seam?cid=313769. Acesso em: 12.09.2014.

ONU. Declaração Universal dos Direitos Humanos: Adotada e proclamada pela resolução 217 A (III) da Assembleia Geral das Nações Unidas em

10 de dezembro de 1948. Brasília: 1998. Disponível em: http://www.mp.ma.gov.br/arquivos/CAOPDH/Declara\%C3\%A7\%C3\%A3o_Universal_dos_Direito s_Humanos_com_introdu\%C3\%A7\%C3\%A3o.pdf. Acesso em: 16.09.2014.

PINKER, Steven. Os anjos bons da nossa natureza: Por que a violência diminuiu. Tradução de Bernardo Joffily e Laura Teixeira Motta. São Paulo: Companhia das Letras, 2013.

POCHMANN, Márcio. Velhos e novos problemas do mercado de trabalho no Brasil. Porto Alegre: Fundação de Economia e Estatística, 1998. Disponível em: <http://revistas.fee.tche.br/index.php/indicadores/article/view/1297/1665>. Acesso em: 01.04.2014.

ROSANVALLON, Pierre. La sociedad de iguales. Buenos Aires: Manantial, 2012.

SALES, Teresa. Trama das desigualdades, drama da pobreza no Brasil. Tese de livre-docência. Campinas: Unicamp, 1992.

SEN, Amartya. Desenvolvimento como liberdade. Tradução de Laura Teixeira Motta. 1 reimp. São Paulo: Companhia das Letras, 2010.

Topo. s/d.

El valor de la democracia. Tradução de Javier Lomelí Ponce. Espanha: Editorial EViejo

SOBOTTKA, Emil Albert. Democracia e desigualdade social. In: BOMBASSARO, Luiz Carlos; KRÜGGELER, Thomas; SOUZA, Ricardo Timm de (Orgs.). Democracia e inclusão social: desigualdade como desafio para a sociedade e a igreja no Brasil. Porto Alegre: Edipucrs, 2009.

SORJ, Bernardo. A democracia inesperada: cidadania, direitos humanos e desigualdade social. Rio de Janeiro: Jorge Zahar Editor, 2004. 
A nova sociedade brasileira. Rio de Janeiro: Jorge Zahar, 2000.

SOUZA, Jessé. A ralé brasileira: quem é e como vive. Belo Horizonte: Editora UFMG, 2009.

STEIN, Ernildo. A questão do método na filosofia: um estudo do modelo heideggeriano. 3 ed. Porto Alegre: Movimento, 1991.

STRECK, Lenio Luiz. Hermenêutica Jurídica e(m) crise. Uma exploração hermenêutica da construção do Direito. 11.ed., atual. e ampliada. Porto Alegre: Livraria do Advogado Editora, 2014.

TOURAINE, Alan. Crítica da Modernidade. Tradução de Elia Ferreira Edel. 10 ed. Petrópolis: Vozes, 2012.

VICENTINO, Cláudio. A criação do Brasil capitalista. In: DEL PIORI, Mary et. al. (Org.). 500 anos de Brasil: histórias e reflexões. São Paulo: Scipione, 1999.

Trabalho recebido em 09 de março de 2019

Aceito em 30 de maio de 2020 